\title{
IMPACT OF DIABETES MELLITUS ON SURVIVAL RATES AFTER HEART TRANSPLANTATION
}

\author{
Helena Bedanova ${ }^{a}$, Jiri Ondrasek ${ }^{a}$, Jan Cerny ${ }^{a}$, Marek Orban ${ }^{a}$, Lenka Spinarova ${ }^{b}$, \\ Petr Hude ${ }^{\mathrm{b}}$, Jan Krejci ${ }^{\mathrm{b}}$, Petr Nemec ${ }^{\mathrm{a}}$ \\ a Center of Cardiovascular and Transplant Surgery, Pekarska 53, Brno, Czech Republic \\ ${ }^{b}$ Department of Cardio-Angiology, St. Anne University Hospital, Pekarska 53, Brno
}

Received: July 14, 2009; Accepted (with revision): October 30, 2009

Key words: Heart transplantation/Diabetes mellitus/Survival analysis

Aims: Heart transplantation (HTx) is the most effective therapy in patients with end-stage heart failure. Diabetesrelated complications are relative contraindications for heart transplantation. The aim of our study was to analyse the impact of DM (diabetes mellitus) at the time of heart transplantation and new-onset post-transplantation DM on long-term survival.

Methods: A retrospective database analysis was performed on all patients who had undergone HTx at our institution between 4/1997 and 9/2007. Patients were divided into three groups: Group A - patients without DM; Group B - patients with new onset of DM after HTx; Group C - patients with DM prior to HTx.

Results: Patients with DM before the surgery were more obese, their BMI was $27.7 \pm 2.90$, compared to groups A and B with BMI of $24.7 \pm 3.37$ and $25.3 \pm 3.64$ respectively $(p=0.0003)$. Patients in group B had statistically significantly higher risk of developing acute rejection $(\mathrm{G} 1 \mathrm{~B}$ and more according to International Society of Heart and Lung Transplantation - ISHLT - classification) $(p=0.0350)$. The incidence of infections between individual groups showed no statistically significant differences $(p=0.5839)$. Five-year survival in group A was $82 \%, 10$-year survival was $73 \%$. Corresponding numbers for group B were $86 \%$ and $78 \%$, for group C $86 \%$ and $83 \%$. Differences between groups were not statistically significant $(p=0.2560)$.

Conclusions: DM in patients after heart transplantation in our study had no effect on long-term survival of patients. Post-transplantation DM increases risk of acute rejections. Pre-transplantation DM was associated with excessive bodyweight or obesity.

\section{INTRODUCTION}

Diabetes mellitus is considered by some transplant centres to be a relative contraindication for cardiac transplantation due to the higher incidence of perioperative and postoperative morbidity. Main concerns are decreased survival, as well as increased incidence of infection, transplant coronary artery disease and possible worsening of DM due to prednisone immunosuppression. Also the development of diabetes mellitus in previously non-diabetic recipients may promote or aggravate these post-transplantation problems ${ }^{1-3}$. A relationship with diabetogenic drugs included in the immunosuppressive regimen was shown more than half of a century $\mathrm{ago}^{4}$. As reported by Jindal ${ }^{5}$, immunosuppressive agents increase the risk of death due to coronary artery disease or stroke by their ability to cause 3 different adverse effects: dyslipidemia, hypertension and hyperglycaemia. Post-transplant diabetes mellitus has emerged as a major adverse effect of immunosuppressants. Based on recent observational study with patients after renal transplantation, the incidence of newly developed diabetes mellitus ranges from $5 \%$ in the 6 -months follow up to $20 \%$ after 10 years posttransplantation ${ }^{6}$. This number is very similar in patients with heart transplant - i.e. 8-20\% (ref. ${ }^{7}$ ).
The objective of this study was to analyse the impact of DM at the time of heart transplantation and new-onset post-transplantation DM on long-term survival and to determine possible risk factors, which could result in the development of post-transplantation DM.

\section{PATIENTS AND METHODS}

Retrospectively, we analysed data from adult patients, who were subject to transplantation at our institution during the past 10 years $(4 / 1997-9 / 2007)$. Mean duration of the follow up was $4.2 \pm 3.8$ years. We assessed the occurrence of acute rejections, bacterial and viral infections, body mass index and most importantly, the long-term survival. Patients were treated with dual-or triple-drug immunosuppression consisting of cyclosporine (CsA) or tacrolimus (Tac), azathioprine or mycophenolate mofetil (after 2001) and steroids. About $10 \%$ of patients remained on a maintenance dose of steroids. After 2001, initial induction therapy with daclizumab was routinely administrated in the direct postoperative phase to all our patients. The study included the total of 150 patients, who were distributed into 3 groups. Group A included 85 patients, who did not suffer from diabetes either before or 
Table 1. Baseline characteristic of patients.

\begin{tabular}{|c|c|c|c|c|c|c|c|}
\hline \multirow{2}{*}{ Group } & \multirow{2}{*}{ Patients } & \multirow{2}{*}{ Age } & \multicolumn{2}{|c|}{ Gender } & \multicolumn{3}{|c|}{ Diagnosis } \\
\cline { 4 - 8 } & Male & Female & IHD & DCM & Other \\
\hline A & 85 & $53 \pm 8$ & $\begin{array}{c}70 \\
(82 \%)\end{array}$ & $\begin{array}{c}15 \\
(18 \%)\end{array}$ & $\begin{array}{c}38 \\
(45 \%)\end{array}$ & $\begin{array}{c}43 \\
(50 \%)\end{array}$ & $\begin{array}{c}4 \\
(5 \%)\end{array}$ \\
\hline B & 27 & $55 \pm 7$ & $\begin{array}{c}21 \\
(91 \%)\end{array}$ & $\begin{array}{c}6 \\
(9 \%)\end{array}$ & $\begin{array}{c}21 \\
(78 \%)\end{array}$ & $\begin{array}{c}5 \\
(18 \%)\end{array}$ & $\begin{array}{c}1 \\
(4 \%)\end{array}$ \\
\hline C & 38 & $56 \pm 5$ & $\begin{array}{c}33 \\
(87 \%)\end{array}$ & $\begin{array}{c}5 \\
(13 \%)\end{array}$ & $\begin{array}{c}27 \\
(71 \%)\end{array}$ & $\begin{array}{c}11 \\
(29 \%)\end{array}$ & 0 \\
\hline
\end{tabular}

IHD - Ischemic Heart Disease, DCM - Dilatative Cardiomyopathy
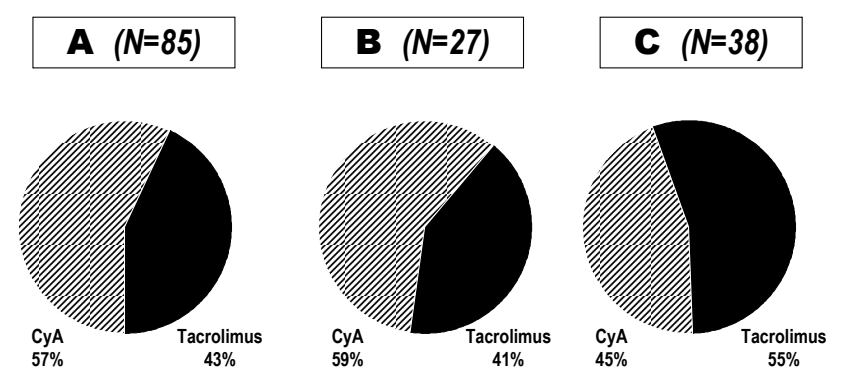

Fig. 1. Immunosuppression.

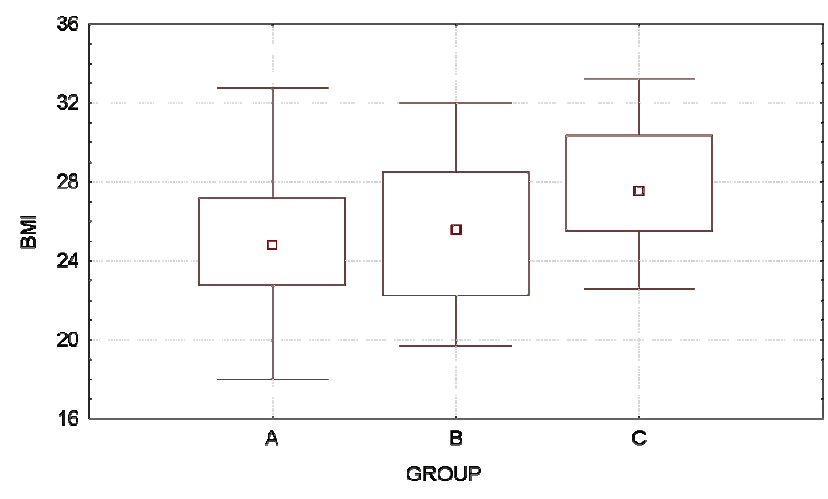

Fig. 2. BMI distribution.

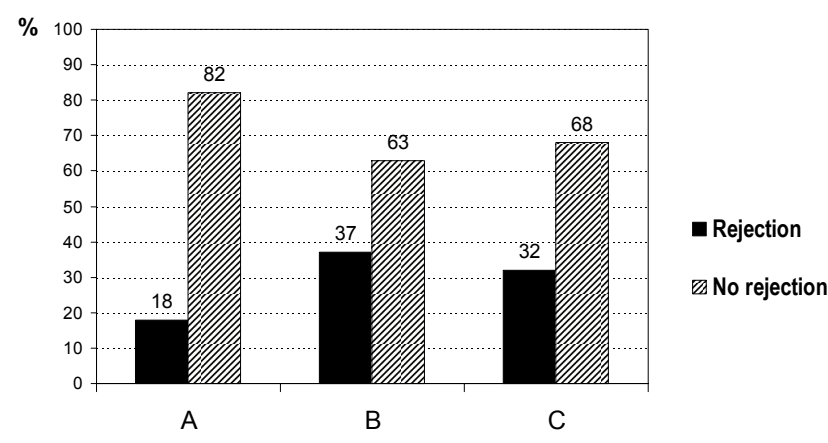

Fig. 3. Rejection by group. after a heart transplantation, group B included 27 patients who developed DM after transplantation and group C included 38 patients with diabetes diagnosed before the transplantation.

\section{STATISTICAL ANALYSIS}

Data were expressed as mean \pm standard deviation from the mean. Selected statistical data were processed into Box \& Whisker plot diagrams and histograms. In order to determine possible relationship between observed endpoints and with respect to the non-Gaussian distribution of these variables, Spearman rank correlation coefficient was used. Shapiro-Wilk test was applied to confirm non-parametric distribution. Qualitative variables were reported as percentages. In order to compare distribution in categoric variables, we used $\chi^{2}$ test of good correlation and in case of $2 \times 2$ contingence tables also the Fisher's exact test. Actual survival data were expressed as KaplanMeir survival estimates ${ }^{8}$. Differences were considered statistically significant when the $p$ value was less than 0.05 .

\section{RESULTS}

Main characteristics of the patient population are presented in Table 1. Mean age of patients in group A was $53 \pm 8$ years, in group B $55 \pm 7$ years and $56 \pm 5$ in group C $(p=0.2775)$. Women accounted for $18 \%$ (15 women) of subjects in group A (the largest proportion), $9 \%(6)$ women in group B and 13\% (5 women) in group C ( $p=$ 0.6612 ). Ischemic heart disease was the indication for transplantation majority of patients in Group B and C (21(78\%) and 27(71\%), respectively). Dilated cardiomyopathy was slightly more prevalent in group $\mathrm{A}$ and affected $47(55 \%)$ of patients ( $p=$ A vs. B 0.100 , B vs. C 0.3325 , A vs. C 0.0180).

Thirty six (43\%) patients from group A, 11 (41\%) patients from group B and 21 (55\%) patients from group $\mathrm{C}$ were treated with tacrolimus, remaining patients were on cyclosporin A. However, the difference between individual groups was not statistically significant $(p=0.1981)$ (Fig. 1). We have not demonstrated higher incidence of post-transplantation diabetes in our selection of patients treated with tacrolimus when compared to patients treated with cyclosporin ( $\mathrm{p}=$ A vs. B 0.133 ).

Patients with pre-operative diagnosis of DM were more obese, their BMI was $27.7 \pm 2.90$ as opposed to groups A and B, where the BMI was $24.7 \pm 3.37$ and $25.3 \pm$ 3.64 respectively ( $p=0.0003$ ) (Fig. 2). The occurrence of acute rejection grade 1B (or higher) according to ISHLT classification was observed in $18 \%$ of patients in group A, $37 \%$ of patients in group B and $32 \%$ of patients in group $\mathrm{C}$. The difference between groups $\mathrm{A}$ and $\mathrm{B}$ was statistically significant $(p=0.0350)$, which means that patients with post-transplantation DM had a higher risk of acute rejection compared to non-diabetic patients (Fig. 3).

Infections were relatively frequent and occurred in more than half of the patients in all three groups. We 
however took into account also mild forms of infection such as type 1 herpes simplex, asymptomatic urinary infections, etc. Slight predominance of viral infections was apparent in all groups (Fig. 4); the proportion of fungal infections was equal in all three groups. Differences in the incidence of infections between individual groups was not statistically significant ( $p=0.5839)$.

Regardless of group, we demonstrated a relationship between age and BMI in all observed parameters: the older were the patients, the higher was their body weight $(p=0.0267)$.

Interestingly, a close relationship between gender and occurrence of acute rejections was noted. Women had nearly $3 \mathrm{x}$ higher risk of acute rejection compared to men $(p=0.0174)$ (Fig. 5).

A 5-year survival in group A was $82 \%, 10$-year survival in group A was $73 \%$. Corresponding numbers for group B were 86 vs. $78 \%$ and in group C 86 vs. $83 \%$ respectively (Fig. 6). Differences between individual groups were not statistically significant $(\mathrm{p}=0.2560)$.

\section{DISCUSSION}

$\mathrm{DM}$ is one of the most prevalent chronic metabolic disorders effecting approximately 176 million people in 2000 and this number should, according to current estimates, increase up to 370 million in 2030 (ref. ${ }^{9}$ ). DM affects many patients before heart transplantation and its occurrence within the first 5 years after the transplantation exceeds $30 \%$. While diabetes mellitus is considered a factor that adversely affects post-transplantation course in patients with renal and liver transplantation ${ }^{10,11}$, the opinion on its role in patients with heart transplantation is not unified. According to some authors, post-transplantation DM increases the risk of acute rejections and infections, increases the incidence of coronary artery disease of the graft and reduces long-term survival of patients with heart transplantation ${ }^{11}$. On the other hand other studies did not confirm these findings ${ }^{13,14}$. Also the opinions regarding the impact of pre-transplantation diabetes are controversial as are the opinions on its effect on long-term survival. According to Czerny, Badovancevic and Meyer ${ }^{15-17}$, pretransplantation diabetes decreases long-term survival (10year) of patients, while according to Russo, Inkedy and Morgan ${ }^{18-20}$ DM does not increase mortality of patients after transplantation and the survival of patients with non-complicated DM is comparable to patients without diabetes. In his work, Marelli ${ }^{21}$ describes decreased 1-year survival of patients with DM, however, the 5-year survival is identical to non-diabetic patients. Based on the results of our database analysis, we conclude that DM in patients after heart transplantation does not influence long-term survival of the patients. These findings were confirmed for both pre-existing DM as well as for de-novo diabetes. Therefore Post-transplantation DM increases risk of acute rejections.

Risk factors associated with the development of post-transplantation diabetes include higher age, obes-
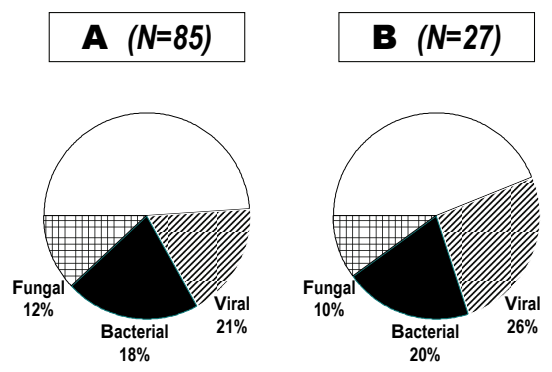

C $(N=38)$

Fig. 4. Infection rate.

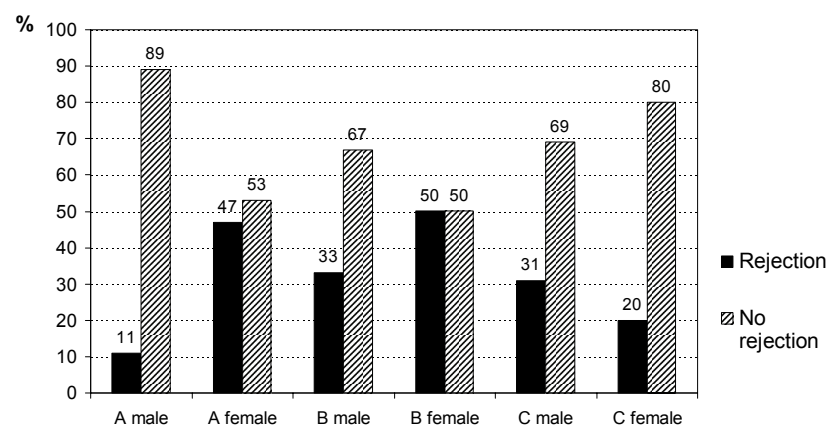

Fig. 5. Rejection depending on group/sex.

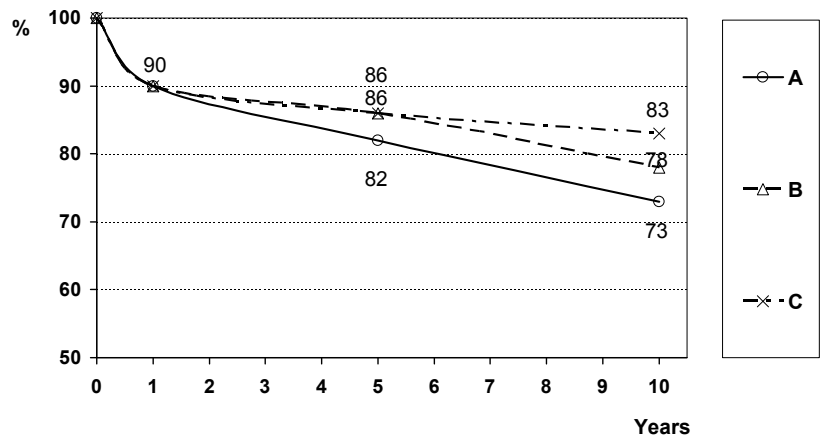

Fig. 6. Survival according to Kaplan-Meier.

ity, Afro-American or Hispanic race, family history, cytomegalovirus infection, treatment with steroids or a type of calcineurine inhibitor. While steroids increase insulin resistance, tacrolimus also decreases insulin production $^{22}$. In contrast to the majority of studies reporting significant impact of tacrolimus on development of post-transplantation diabetes ${ }^{23-25}$, we found a no higher incidence of post-transplantation diabetes in our selection of patients treated with tacrolimus than patients treated with cyclosporin. This result agrees with the results of recently published DIRECT-trial (Diabetes incidence after renal transplantation: Neoral C2 monitoring versus Tacrolimus). In this study including 690 patients after renal transplantation, treatment with tacrolimus was not associated with increased incidence of newly developed DM or higher fasting glucose levels in the first 6 months after transplantation when compared to patients treated with cyclosporin ${ }^{26}$. 
The limitations of this study include the retrospective design and relatively small number of patients in groups $\mathrm{B}$ and $\mathrm{C}$. The total number of patients in these two groups also excluded the further separation of subjects into subgroups, particularly subgroups of patients treated before and after the year 2001, when the protocol for immunosuppression had changed and all patients started to receive induction therapy (monoclonal antibody daclizumab) and azathioprine was replaced with mycophenolate mofetil.

Differentiation of the study population according to the type of DM would have been definitely interesting but was not possible due to the retrospective nature of our study and very probably with expected low incidence of type 1 the statistical analysis would be somewhat inadequate. For the same reason we were not able to validate the compensation of DM since glycated hemoglobin HbA1c was not available in all subjects.

The prevalence of donor diabetes could not be assessed, but appears to be an unlikely factor influencing survival given the young mean donor age of 34 and recent data indicating that only very few donor characteristics have actually significant impact on recipient outcome $e^{27,28}$.

It would have been of utmost interest to determine the impact of cardiac allograft vasculopathy (CAV), which is one of the major factors limiting long-term survival in heart transplant patients. Currently, intravascular ultrasound (IVUS) is considered as a golden standard for the diagnosis of CAV. It is a widely accepted fact that IVUS is more sensitive both in the diagnostics of CAV and in determination of the degree of coronary artery impairment compared to selective coronary angiography. IVUS enables reliable stratification of the patient after OTS from the CAV perspective, because the low degree of intimal impairment correlates very well with the prognosis of the patient ${ }^{29,30}$. Therefore, even though we have used IVUS exams in our patients over the past couple of years, the data were not consistent enough to be used in this database analysis. Apropos incomplete data on coronary interventions, these patients could not be included in the study either.

Based on these results of our study, we can conclude that post-transplantation diabetes mellitus in patients participating in our study increases the risk of acute rejections and pre-transplantation diabetes increases the incidence of obesity and excessive body weight. DM had no effect on long-term survival of patients in our study. Despite this fact, aggressive management of pre-transplantation diabetes and early detection of post-transplantation diabetes according to current guidelines appears crucial ${ }^{31}$.

\section{ACKNOWLEDGEMENTS}

We would like to express our sincere gratitude for help with the database search to Irena Kuzmova and Jana Rutarova. We would also like to thank Edita Houbova, Ivan Zinrak and Jiri Cetkovsky for their contribution with the preparation of the manuscript.

\section{REFERENCES}

1. Bangratz S. Complacations in heart transplantation: diagnosis and treatment. Presse Med 2001; 30(24):8-12.

2. Morgan JA, John R, Weinberg AD, Colletti NJ, Mancini DM, Edwards NM. Heart transplantation in diabetic patients: a decade review of 161 patients at Columbia Presbyterian. J Thorac Cardiovasc Surg 2004; 127(5):1486-92.

3. Higgins J, Pflugfelder PW, Kostuk WJ. Increased Morbidity in diabetic cardiac transplant recipients. Can J Cardiol 2009; 25(4):1259 .

4. Starzl TE. Postoperative and surgical complications. In: Starzl TE Experience in renal transplantation. Philadelphia: Sauders; 1964:117.

5. Jindal RM, Sidner RA, Milgrom ML. Post-transplant diabetes mellitus: the role of immunosuppression. Drug Saf. 1997; 16(4):242-57.

6. Durrbach A. Diabetes after transplantation. Nephrol Ther 2006; 5(3):S197-9.

7. Landowski JS, Kormos RL, Uretsky BF, Lee A, Curran M, Clark R, Armitage JM, Griffith BP, Hardesty RL. Posttransplantation diabetes mellitus in heart transplant recipients. J Heart Transplant 1989; 8:181-9.

8. Kaplan EL, Meier P. Nonparametric estimation from incomplete obsarvations. J Amer Statist Ass 1958; 53:457-81.

9. World Health Organisation Diabetes Database. Available at: http:// www.who.int/ncd/dia/databases4.htm. Accessed 28.January 2003.

10. Baid S, Cosimi AB, Farrel ML, Schoenfeld DA, Feng S, Chung RT, Tolkoff-Rubin N, Pascual M. Posttransplant diabetes mellitus in liver transplant recipients: Risk factors, temporal relationship with hepatitis $\mathrm{C}$ virus allograft hepatitis, and impact on mortality. Transplantation 2001; 72(6):1066-72.

11. Reddy KS, Stablein D, Taranto S, Stratta RJ, Johnston TD, Waid TH, McKeown JW, Lucas BA, Ranjan D. Long-term survival following simultaneous kidney-pancreas transplantation versus kidney transplantation alone in patients with type 1 diabetes mellitus and renal failure. Am J Kidney Dis 2003; 41(2):464-70.

12. Marchetti P. New-outset diabetes after transplantation. J Heart Lung Transplant. 2004; 2 3(S5):194-2001.

13. Bangratz S. Complications in heart transplantation: diagnosis and treatment. Presse Med. 2001; 20(24):8-12.

14. Kobashigawa JA, Starling RC, Mehra MR, Kormos RL, Bhat G, Barr ML, Sigouin CS, Kolesar J, Fitzsimmons W. Multicenter retrospective analysis of cardiovascular risk factors affecting long-term outcomes of de novo cardiac transplant recipients. J Heart Lung transplant. 2006; 25(9):1063-9.

15. Czerny M, Sahin V, Fasching P, Zuckermann A, Zimpfer D, Kilo J, Wolner E, Grimm M. The impact of diabetes mellitus at the time of heart transplantation on long-term survival. Diabetologia. 2002; 45(11):1498-508.

16. Radovancevic B, Konuralp C, Vrtavec B, Radovancevic R, Thomas $\mathrm{CD}$, Zaqqa M, Vaughn WK, frazier $\mathrm{OH}$. Factors predicting 10year survival after heart transplantation. J Heart Transplant. 2005; 24(2):156-9.

17. Meyer SR, Modry DL, Norris CM, Pearson GJ, Bentley MJ, Koshal A, Mullen JC, Rebeyka IM, Ross DB, Wang S. Pretransplant diabetes, not donor age, predicts long-term outcomes in cardiac transplantation. J Card Surg. 2006; 21(2):117-24.

18. Russo MJ, Chen JM, Hong KN, Stewart AS, Ascheim DD, Argentino M, Mancini DM, Oz MC, Naka Y. Survival after heart transplantation is not diminished among recipients with uncomplicated diabetes mellitus: an analysis of the United Network of Organ Sparing database. Circulation. 2006; 114(21):2206-7.

19. Inkeda Y, Tenderech G, Zittermann A, Minami K, Koerfer R. Heart transplantation in insulin-treated diabetic mellitus patients with diabetes-related complications. Transpl Int. 2007; 20(6):528-33.

20. Morgan JA, John R, Weinberg AD, Colleti NJ, Mancini DM, Edwards NM. Heart transplantation in diabetic recipients: a decade review of 161 patients at Columbia Presbyterian. J Thorac Cardiovasc Surg. 2004; 127(5):1486-92.

21. Marelli D, Laks H, Patel B, Kermani R, Marmureanu A, Patel J, Kobashigawa J. Heart transplantation in patiens with diabe- 
tes mellitus in the current era. J Heart Lung Tranplant. 2003; 22(10):1091-7.

22. van Duijnhoven EM, Boots JM, Christiaans MH, van Hoff JP. Metabolic aspects of tacrolimus in renal transplantation. Consequences for the choice of an immunosuppressive regiment and for the management of post-transplant diabetes mellitus. Minerva Urol Nephrol. 2003; 55(1):33-42.

23. Martinez-Dolz L, Almenar L, Martinez-Ortiz L, Arnau MA, Chamorro C, Moro J, Osa A, Rueda J, Garcia C, Palencia M. Predictive factors for development of diabetes mellitus post-heart transplant. Transplant Proc. 2005; 37(9):4064-6.

24. Grimm M, Rinaldi M, Yonan NA, Arpesella G, Arizon Del Prado JM, Pulpon LA, Villemont JP, Frigerio M, Rodriguez Lambert JL, Crespo-Leiro MG, Almenar L, Duveau D, Ordonez-Fernandez A, Gandjbekhch J, Maccherini M, Laufer G. Superior prevention of acute rejection by tacrolimus vs. Cyclosporine in heart transplant recipients-a large European trial. Am J Transplant. 2006; 6(6):1387-97.

25. Moro JA, Martinez-Dolz L, Almenar L, Martinez-Ortiz L, Chamorro C, Garcia C, Arnau MA, Rueda J, Zorio E, Salvador A. Impact of diabetes mellitus on heart transplant recipients. Rev Esp Cardiol. 2006; 59(10):1033-7.

26. Vincenti F, Friman S, Scheuermann E, Rostaing L, Jenssen T, Campistol JM, Uchida K, Pescovitz MD, Marchetti P, Tuncer M, Citterio F, Wiecek A, Chadban S, El-Shahawy M, Budde K, Goto $\mathrm{N}$. Results of an international, randomized trial comparing glucose metabolism disorders and outcome with cyclosporine versus tacrolimus. Am J Tranpslant 2007; 7(6):1506-1514.

27. Chen JM, Sinha P, Rajasinghe HA, Suratwala SJ, McCue JD, McCarty MJ, Caliste X, Hauff HM, John R, Edwards NM. Do donor characteristics really matter? Short-and long-term impact of donor characteristics on recipient survival, 1991-1999. J Heart Lung Transplant 2002; 21:608-10.

28. Taylor DO, Edwards LB, Boucek MM. Registry of the International Socienty for Heart and Lung Transplantation: Twenty -third official adult heart transplantation report-2006. J Heart Transplant 2006; 25:869-79.

29. Kobashigawa JA, Laks H, Wu G, Patel J, Moriguchi J, Hamilton M, Fonarow G, Fishbein M, Ardehali A. The University of California at Angeles heart transplantation experience. Clin Transpl. 2005; $173-85$.

30. Kobashigawa JA, Tobis JM, Starling RC, Tuzcu EM, Smith AL, Valantine HA, Yeung AC, mehra MR, Anzai H, Oeser BT, Abeywickrama KH, Murphy J, Crestin N. Multicenter intravascular ultrasound validation study among heart transplant recipients: outcomes after five years. J Am Coll Cardiol. 2005; 45(9):1532-7.

31. Davidson J, Wilkinson A, Dantal J, Dotta F, Haller H, Hernández D, Kasiske BL, Kiberd B, Krentz A, Legendre Ch, Marchetti P, Markell M, Van Der Woude FJ, Wheeler DC. New-onset diabetes after transplantation: 2003 international consensus guidelines. Transplantation 2003; 75:SS3-SS24. 
